\title{
Vinca-Domain Binding Agent
}

National Cancer Institute

\section{Source}

National Cancer Institute. Vinca-Domain Binding Agent. NCI Thesaurus. Code C67422.

Any of a class of anti-mitotic compounds that bind to the vinca site of the beta tubulin subunit, a region located within the middle domain of the tubulin structure and corresponding with a residue sequence approximating $177-215$. The agent binds to the vinca site to produce a conformational change in the protofilament structure and at high concentrations, to induce the formation of spirals and crystal agg regates; these changes impair the polymerization of tubulin dimers and thereby, prevent the assembly of microtubules. The subsequent decrease in the amount of formed microtubules causes disassembly of the mitotic spindle resulting from instability of the structure during the mitotic interphase, eventually leading to cell cycle arrest and/or apoptosis. Vinca-site binding agents include natural compounds isolated from the periwinkle (Catharanthus roseus, formally, Vinca roseus) plant and synthetic compounds. 